Nunes, A, \& Hernandez, K.D. (2020). Autonomous taxis and public health: High cost of high opportunity cost? Transportation Research Part A: Policy and Practice. Vol 138, 28 - 36.

\title{
Autonomous Taxis \& Public Health: High Cost or High Opportunity Cost?
}

\author{
Ashley Nunes ${ }^{1,2 \dagger}$ and Kristen D. Hernandez ${ }^{1}$ \\ ${ }^{1}$ Massachusetts Institute of Technology \\ Cambridge, MA, 02139, USA \\ ${ }^{2}$ Harvard Law School \\ Cambridge, MA 02138, USA \\ † anunes@mit.edu
}


Nunes, A, \& Hernandez, K.D. (2020). Autonomous taxis and public health: High cost of high opportunity cost? Transportation Research Part A: Policy and Practice. Vol 138, 28 - 36.

\section{Summary}

Passenger vehicles are a major source of air pollution, exposure to which increases respiratory disease risk, amplifies life-threatening conditions and burdens the public purse. The negative externalities associated with these vehicles rise further when road accidents are considered. Almost all such accidents involving fatalities transpire when private users are in single vehicle incidents or collide with each other. Though autonomous vehicle technology can mitigate these effects, widespread adoption and proliferation demands cost competitiveness with the status quo; namely, personally owned and operated, conventional vehicles. Here we show that this prospect may - in a commercially owned and operated enterprise - be unlikely. Causal factors of relevance include low capacity utilization rates and impracticable profit expectations. In a single ridership 'autonomous taxi' model, we find capacity utilization rates would need to improve from 52 percent to 100 percent and profits lowered by 37 percent (from 27 cents to 17 cents on a permile basis) for autonomous taxis to offer fares that are comparable with personally owned, conventional vehicles. In a multiple ridership model, the affordance of these fares requires a 30 percent increase in vehicle occupancy (from 1.67 to 2.2 ) and a 75 percent increase (1.67 to 2.92) were even lower fares offered to incentivize shared, autonomous taxi use over personally owned, conventional vehicles. We conclude that consideration of the opportunity costs of driving are integral to the widespread adoption of a technology that may dramatically improve public health outcomes.

\section{Keywords}

Autonomous taxis, Mobility as a Service, Conventional Vehicles, Public Policy

\section{Highlights}

- Realizing public health benefits of autonomous vehicle technology demands cost competitiveness with the status quo

- Autonomous taxis are costlier than conventionally driven vehicles

- Important cost drivers are 'deadweight' miles and impracticable margin expectations

- Marketing opportunity costs are integral to realizing public health benefits of autonomous vehicle technology 
Nunes, A, \& Hernandez, K.D. (2020). Autonomous taxis and public health: High cost of high opportunity cost? Transportation Research Part A: Policy and Practice. Vol 138, $28-36$.

\section{Introduction}

Although personal vehicle ownership promotes economic mobility (1), it comes at a price. Cars, vans and sport utility vehicles are a dominant source of air pollutants (2). These include carbon monoxide $(\mathrm{CO})$, nitrogen oxides $\left(\mathrm{NO}_{\mathrm{x}}\right)$, volatile organic compounds (VOCs) and particulate matter, exposure to which contribute increases societal morbidity and mortality risk $(3,4)$. The ensuing fiscal toll is not insignificant. In 2015, emission-related harm caused by passenger vehicles in ten American states alone totaled $\$ 37$ billion. Of that, some $\$ 24$ billion was related to health expenditures such as work-loss days, asthma-related attacks and premature deaths (5).

Highly automated vehicles (HAVs) - vehicles that drive themselves some or all of the time - promise relief $(6,7)$. By shifting responsibility for higher-order control functions from humans to machines, the technology facilitates so-called 'eco-driving;' a practice set that maximizes an engine's operating efficiencies while minimizing repeated, energy intensive braking-acceleration cycles $(8,9)$. When coupled with platooning, the result is significant declines in emissions that ultimately improve public health outcomes (10).

HAVs offer an additional public health benefit - namely, reductions in automobile crashes. In the United States alone, crash-related fatalities represent almost four out of every ten "unintentional injury" deaths - deaths that do not result from old age, disease, homicide or suicide (11). HAVs promise to reduce these figures by eliminating driver-related errors blamed in most automobile crashes (12). Consequently, improved road safety is one of the key benefits associated with HAVs and one of the most influential features considered when determining the technology's desirability (13).

However, leveraging the public health benefits of HAVs demands incentivizing consumer procurement of the technology - an unlikely prospect given its cost prohibitive nature $(6,7)$. Although cost-reductions owing to learning effects are expected, the ensuing price points of HAVs are unlikely to be comparable to non-HAVs. This is already reflected in existing automotive pricing where the inclusion of partial (but not full) automation features like adaptive cruise control, night vision and pedestrian detection make vehicles equipped with these systems more expensive than their non-equipped counterparts (7).

HAVs may admittedly bestow safety benefits that consumers value thereby making cost competitiveness with CDVs an unnecessary precondition for widespread adoption. Such reasoning dictates that consumers are willing to incur out-of-pocket expenditures in exchange for greater vehicular safety offered by HAVs. However, research demonstrates discrepancies between stated and revealed preference owing to cost considerations - one that ultimately produces a slow adoption curve for safety-critical automotive systems (14).

HAV-related cost impediments may be circumvented by offering the technology for-hire: a setup that - like the existing taxi industry - distributes expenditures over a large number of 
consumers thereby making self-driving technology more affordable ${ }^{1}$. Existing literature suggests that so-called 'autonomous taxis' (ATs) could deliver further savings to consumers via reductions in fleet operator wage expenditures $(10,16-18)$ as the shift of vehicular control duties from humans to machines diminishes the necessity to employ (and hence pay) human drivers. Consequently, the affordability of hailing ATs - influenced in large measure by the absence of human drivers features prominently in current AT-related discourse $(7,10,13,16-18)$.

Our work scrutinizes the fiscal viability of this concept. In addition to the inclusion of conventional expenditures associated with commercial mobility on demand services, we also consider - and subsequently control for - expenditures associated with safety oversight provision, profits associated with current commercial fleet operators and applicable operating characteristics. The derived AT fare estimates are then compared to the cost of conventionally driven vehicle (CDV) ownership models (i.e., the status quo).

Our efforts are motivated by two intuitive yet important questions. Firstly, can ATs deliver - all else being equal - a cost proposition to consumers that is equivalent to (or better than) CDV ownership models? If not, what are the conditions necessary to achieve the aforementioned proposition? Cost competitiveness is key to realizing the positive public health externalities associated with self-driving technology as consumers - incentivized by lower prices - forgo CDV ownership in favor of ATs.

${ }^{1}$ This approach may further improve public health outcomes by meeting travel demand using fewer vehicles which reduces congestion-related emissions $(11,15)$. 
Nunes, A, \& Hernandez, K.D. (2020). Autonomous taxis and public health: High cost of high opportunity cost? Transportation Research Part A: Policy and Practice. Vol 138, 28 - 36.

\section{Method}

We begin by first selecting a key auto market - namely, San Francisco. The city and its surroundings have been designated one of the most polluted and accident-prone regions in the United States making it an appropriate choice for realizing the totality of the public health benefits associated with ATs.

The cost proposition associated with realizing this vision is ascertained through the lens of applicable expenditures and compared against costs of owning CDVs. Figures derived from publicly available sources and associated with the current vehicle for-hire industry (i.e., commercial taxis) are - where applicable - leveraged for an estimation of AT fares (see Supplementary Information for details). Concerns regarding the inclusion of specified cost parameters (such as licensing costs), their magnitude and their subsequent impact on the cost proposition of ATs is addressed through elasticity testing and sensitivity analysis. This process quantifies the degree of change in fare-per-mile estimates for a given change in an AT-related expenditure.

AT-related expenditures accounted for include vehicle financing, licensing, insurance, maintenance, cleaning, fuel and safety oversight. Descriptions of these expenditures are summarized below.

Vehicle Financing considers the total cost of AT procurement. This includes the initial acquisition cost - that is, the down payment for the vehicle - and the cost of financing the payment balance. Payments are indexed across the entire lifespan of the vehicle.

Licensing considers the cost of regulatory authorization and registration required of commercial fleet operators to offer mobility-on-demand services. The magnitude of these costs fluctuates based on the regulatory environment and other market forces.

Insurance considers expenditures associated with protecting fleet operators against accident and theft-related financial losses. In the event that losses are incurred, premiums paid by the fleet operator are used to fund financial relief packages subject to the terms and conditions of the insurance plan.

Maintenance considers the cost performing routine inspection on and where applicable, replacement of a vehicle's underlying components. Components of note include (but are not limited to), air filters, transmission, brakes, struts and sensors.

Cleaning considers expenditures associated with providing detailing services. These services include (but are not limited to) interior vacuuming, interior polishing, mirror washing, tire cleaning, trim cleaning and window washing.

Fuel considers expenditures associated with AT propulsion. These vehicles are - similar to conventionally driven taxis in the target market - assumed to have hybrid powertrains. This facilitates the maximization of fuel economy, thereby reducing cost.

Safety Oversight considers the cost of supervisor control. Because driverless does not mean humanless, ATs will be overseen by human operators. A one-to-many supervisory control setup is 
Nunes, A, \& Hernandez, K.D. (2020). Autonomous taxis and public health: High cost of high opportunity cost? Transportation Research Part A: Policy and Practice. Vol 138, 28-36.

envisioned to realize cost benefits associated with economies of density $(19,20)$. Given declining marginal gains, the maximum number of ATs monitored by one operator is capped at 50 .

Summation of the aforementioned expenditures represents the per mile production costs incurred by an AT fleet operator. These costs are further adjusted to reflect fleet operator profits and the AT's capacity utilization rate.

Operator Profit represents the rate of return fleet operators realize via service operation. The prevailing for-hire mobility setup among global commercial fleet operators entails leasing vehicles to independent contract drivers $(21,22)$. Operating costs (e.g., vehicle financing, insurance, maintenance) are borne by fleet operator and passed along to drivers via a fee (see Supplementary Information section). Profits realized by the fleet operator represents the difference between the fee levied by the operator and costs incurred by that operator.

Capacity Utilization Rate is defined as the percentage of miles travelled by a taxi with a fare paying passenger on board. To ensure fiscal solvency, fleet operators pass expenditures associated with 'empty miles' along to consumers. Hence, accounting for this factor is of particular importance when estimating fares.

Consideration of the totality of the aforementioned expenditures and factors yield comprehensive fare-per mile estimates. This estimate is derived using the formula:

Fare per Mile $=\frac{\text { Financing }+ \text { Licensing }+ \text { Insurance }+ \text { Maintenance }+ \text { Cleaning }+ \text { Fuel }+ \text { Safety Oversight }+ \text { Profit }}{\text { Capacity Utilization Rate }}$

The derived fare-per-mile estimates are then compared against CDV ownership expenditures to assess cost competitiveness (Table 1). CDV ownership costs considered include vehicle financing, licensing, insurance, maintenance, cleaning, fuel and parking. Figures leveraged for CDV ownership cost computation prioritize consumer price sensitivity. Consequently, CDV ownership costs may be higher were consumers to prioritize non cost-based characteristics of input parameters (e.g., were a CDV owner to choose more expensive urban parking structures over relatively inexpensive, street parking). 
Nunes, A, \& Hernandez, K.D. (2020). Autonomous taxis and public health: High cost of high opportunity cost? Transportation Research Part A: Policy and Practice. Vol 138, 28 - 36.

\section{Results}

Fares drop as AT-related costs are distributed in a one-to-many supervisory control setup (Fig. 1a). Successive additions show declining marginal utility and do not approach cost competitiveness with CDV ownership.

Elasticity testing of AT-related input costs and parameters reveals several effects (Table 2). Firstly, capacity utilization approaches unit elasticity, levying the greatest influence on fareper-mile estimates compared to other cost inputs and parameters. This is followed by profit-permile and licensing expenditures respectively, the influence of these variables growing as economies of density are further leveraged. Despite this growth, AT fares remain inelastic in response to changes in profit-per-mile estimates and licensing expenditures. Price inelasticity is also observed in response to changes in safety-oversight related expenditures.

In lieu of the aforementioned results, sensitivity analysis is applied to identify the conditions under which AT services could become cost competitive with CDVs. Focus is placed on the most influential inputs/parameters AT fleet operators - namely capacity utilization and envisioned profit-per mile. This focus is intentional as reductions in input costs/parameters like financing, maintenance and insurance licensing depend on a complex interaction between and across economic actors and conditions and hence are considered more effortful for AT fleet operators to influence. We further note that elimination of these costs would - in their entirety still produce a cost proposition that is higher than CDVs.

We find that while capacity utilization levies the greatest influence on fares, and current utilization rates leave room for improvement, achieving maximum utilization yields a cost proposition that is still higher than CDV (Fig. 1b). Cost competitiveness under these conditions demands leveraging of economies of density and lowering envisioned profits over realized estimates observed by fleet operators today (Fig. 1c). 
Nunes, A, \& Hernandez, K.D. (2020). Autonomous taxis and public health: High cost of high opportunity cost? Transportation Research Part A: Policy and Practice. Vol 138, 28 - 36.

\section{Discussion}

While HAV technology has the potential to significantly improve public health outcomes through emission and road crash reductions $(7,10,13)$, doing so ultimately demands cost competitiveness with CDVs. Our results demonstrate this may - all else being equal - be a difficult proposition.

Using San Francisco as a test market, we find that were AT services offered with applicable expenditures and parameters analogous to the current taxi industry, fares would - on a per mile basis - be costlier than owning a CDV. The primary influencers of this differential are not financing, maintenance or insurance-related expenditures. Nor is the cost differential primarily influenced by licensing costs. These variables could - despite their sizable cumulative outlay - be eliminated in their entirety and AT fares would still remain - on a per mile basis - costlier than CDVs. Instead, the lack of cost competitiveness between commercially owned and operated ATs and CDV ownership models is principally influenced by the AT's capacity utilization rate.

Utilization rates may admittedly be improved upon. Studies show the deployment of centrally controlled taxi fleets can reduce utilization inefficiencies associated with conventional taxi operations $(23,24,25)$. However, our sensitivity testing demonstrates that achieving maximum utilization - that is, having 100 percent of AT miles travelled with a fare paying passenger onboard - would still leave ATs fiscally uncompetitive with CDVs (Fig. 1b). AT fares would remain despite the admittedly unrealistic nature of the aforementioned prospect - higher than CDV ownership. Invalidating this effect for consumers inclined to use CDVs over ATs requires - all else being equal - capacity utilization maximization and a 37 percent reduction in estimated fleet operator profits from 27 cents to 16 cents on a per-mile basis. This is noteworthy given envisioned profit expectations of AT fleet operators are either roughly consistent with or exceed the profit estimates we associate with today's taxi industry (26). Moreover, these expectations are absent consideration of the fleet's capacity utilization rate that further exacerbates the aforementioned effect (27).

Our findings admittedly presume carriage of a single fare-paying passenger. Were a ridepooling model leveraged, one where fares are equally divided among multiple passengers in the vehicle, the resulting cost proposition could - on a per passenger per mile basis - become competitive with CDV ownership. We examine the viability of this setup, acknowledging that complete realization of HAVs' public health benefits may necessitate high occupancy travel (28). We find that offering AT fares that are - on a per mile basis - equivalent to CDV ownership requires increasing existing vehicle occupancy rates from 1.67 passengers per vehicle to 2.2 (Fig. 2a) (29). This figure rises further (from 1.67 to 2.92) were fiscal incentives, specifically a 25 percent fare reduction (from $\$ 0.72$ to $\$ 0.54$ ) designed to encourage high occupancy travel (30) applied to improve the value proposition of ATs over CDVs (Fig. 2b). This is noteworthy for two reasons. Firstly, consumers show a strong aversion towards for-hire high occupancy travel - an effect driven largely by elongated travel time uncertainty, and to a lesser extent, privacy considerations (31-33). Secondly, incentivizing for-hire high occupancy travel as a means of improving the value proposition of ATs relative to CDVs is not - to our knowledge - part of public discourse. 
Nunes, A, \& Hernandez, K.D. (2020). Autonomous taxis and public health: High cost of high opportunity cost? Transportation Research Part A: Policy and Practice. Vol 138, 28 - 36.

\section{Opportunity Cost Considerations}

Although our assessment of the fiscal viability of ATs appears bleak, this may be driven by our omission of opportunity costs - the unrealized flow of utility from the alternatives a choice (in this case, CDV ownership) displaces. Consideration of this cost is admittedly important given productivity losses associated with the time-consuming task of driving (34). We find that consideration of opportunity cost significantly improves the cost competitiveness of ATs. Previously identified (and existing) operational impediments - specifically, supply-demand matching inefficiencies, profit expectations and vehicle occupancy rates - could persist and ATs would still - when consideration of driving's opportunity costs are maximized - offer a value proposition that is nearly equivalent to or better than CDV ownership (Fig. 3a).

This finding is both problematic and promising. On the one hand, neoclassical economics presumes opportunity costs are accounted for when evaluating a potential purchase. Consumers are assumed to routinely generate an exhaustive set of alternatives and successively simulate the utility of various combinations against the utility of the focal good whose purchase is being considered. However, empirical research suggests consumers fail to fully consider these combinations, resulting in opportunity cost neglect (35). In the present case, the prevalence of said neglect may - absent improvements in supply-demand matching inefficiencies, lower profit expectations and changes in for-hire high occupancy travel preferences - incentivize consumers to retain CDV ownership models over utilizing ATs. This would ultimately impede the realization and proliferation of the positive public health externalities associated with HAVs.

However, opportunity cost neglect may be circumvented through explicit messaging and salience, both of which have been shown to markedly affect consumer preferences $(35,36)$. This gives HAV advocates a mechanism to incentivize the abandonment of CDV ownership in favor of HAVs. Marketing campaigns aimed at improving public health outcomes using ATs must explicitly emphasize the high cumulative costs (i.e., ownership and opportunity combined) CDVs impose when compared against ATs. These campaigns should also draw attention to the temporal totality consumers spend on driving (34) - time that, assuming ATs are appropriately designed, may be used engaging in more productive activities.

\section{Public Policy Implications}

Our findings have important implications for policy makers. Thus far, realization of the positive public health externalities of HAVs have been largely tied to resolving regulatory, ethical and most importantly, technological challenges $(7,13,37)$. Government and private entities alike, contend that resolution of these challenges alone will incentivize consumers to leverage the technology thereby improving public health outcomes. HAV-related spending programs reflect this reality (37-39). Our work suggests this approach may warrant reconsideration given the technology's cost-prohibitive nature. We find that - assuming current market conditions persist HAV technology struggles to achieve price parity with CDV ownership owing to factors that warrant greater attention in HAV-related discourse (10,16-18).

One approach towards achieving cost parity entails communicating the opportunity costs of driving. We find that doing so significantly improves the value proposition of AT, resulting in 
near cost equivalence with CDV ownership. Yet, this reality has been largely ignored by government and private entities alike. For example, since 2014, the U.K. government has invested over $£ 120$ million on self-driving technology projects, none of which address the importance of communicating opportunity cost savings to consumers (39). A similar pattern emerges in the United States and China where the fiscal viability of for-hire HAVs have been overlooked by a singular focus on addressing the technological and infrastructure challenges associated with bringing the technology to market (40).

Our results suggest that this approach may be insufficient for the public health benefits associated with HAV technology to be realized $(13,41)$. Circumventing the ensuing reality will require the careful development and deployment of marketing campaigns that explicitly highlight the opportunity costs of driving ${ }^{2}$. While such campaigns have historically been overlooked in HAV-related discourse, our results suggest they warrant serious consideration by private and public stakeholders as a mechanism to improve the cost proposition of ATs over CDVs.

Marketing campaigns may also facilitate shifts in consumer preference away from CDV ownership in favor of ATs usage by changing attitudes towards high occupancy travel. Ridepooling represents an effective means of realizing the public health benefits of HAV technology and this approach remains one that doesn't depend on addressing the utilization and profitability challenges discussed thus far. However, the effectiveness of campaigns that encourage ridepooling will require addressing elongated travel time uncertainty and privacy considerations that are characteristic of high occupancy travel (31-33).

\section{Conclusion \& Limitations}

The findings presented here should not be interpreted as evidence that the public health benefits - specifically, reductions in vehicle emissions and motor vehicle crashes - associated with HAV technology cannot be realized in a fleet operator model. Rather, we postulate that achievement of the aforementioned result may not - contrary to current public discourse - be fiscally viable solely through human resource-related cost reductions associated with HAV technology, most notably through the elimination of driver wages $(10,16-18,43)$.

We conclude by acknowledging four limitations of our work. Firstly, our analysis does not consider ancillary revenue streams. These may be leveraged by AT operators to offset losses associated with offering cost competitive fares to existing CDV owners. Autonomous around-town food deliveries for example, represents one way to achieve this goal. So does the monetization of rider behavior which HAV fleet operators have long expressed an interest in as a means of raising revenue. However, the economics of this approach are not well understood, and existing data

\footnotetext{
${ }^{2}$ Consideration of the social costs of driving (e.g., congestion and accidents) further improve the value proposition of ATs. However, estimated savings are significantly smaller than those produced through opportunity cost consideration $(10,40,42)$.
} 
Nunes, A, \& Hernandez, K.D. (2020). Autonomous taxis and public health: High cost of high opportunity cost? Transportation Research Part A: Policy and Practice. Vol 138, 28 - 36.

provides little evidence that revenue gains from ancillary sources may offset losses associated with offering lower fares (44).

Secondly, our analysis emphasizes lowering the user costs of ATs. An alternate approach would be to raise the cost of CDV ownership. This policy has been adopted in countries like Singapore where an expensive bidding system - justified on land scarcity grounds - has made CDV ownership cost prohibitive (45). Our work does not consider this policy lever given the political resistance it would invariably face (particularly in already highly motorized countries) and the fact that migration away from CDV ownership models towards ATs are predicated on the latter's improved cost proposition relative to the status quo. Existing HAV discourse does not - to our knowledge - emphasize altering existing ownership costs of CDV to make ATs more attractive (7, $13)$.

Thirdly, our modeling efforts incorporate aggregated daily capacity utilization rates; i.e., we do not consider momentary travel demand fluctuations that are an inevitable consequence of the modern socioeconomic system. The homogeneity of global working times concentrates societal travel habits to the early morning and late afternoon hours. This pattern may - in a mobility ecosystem serviced by ATs - allow fleet operators to scale back deployment during demand troughs thereby reducing variable costs of deploying ATs. Whether or not doing so significantly improves the cost proposition of ATs over CDV should be further explored. However, we note that asset downtime - to our knowledge - being promulgated as integral towards ensuring AT cost competitiveness.

Finally, our findings are confined to a single market. Other cities may - absent opportunity cost considerations - offer an improved cost proposition for AT services. Capacity utilization rates - the largest AT cost influencer - have been found to globally vary. In Beijing, utilization rates approach nearly 58\% (22); in Los Angeles, 65\% (23) and Singapore, 66\% (46). However, these figures - while higher than our targeted market - do not approach their maximal threshold. Furthermore, capacity utilization maximization would still leave ATs uncompetitive with CDV ownership as the return demanded by AT fleet operators may eliminate the competitive advantage associated with forgoing human drivers. Nevertheless, we acknowledge the applicability of our findings should be investigated in other markets as should the identification of alternative business models that would improve the cost proposition of ATs for fleet operators and consumers alike.

\footnotetext{
${ }^{3}$ The aforementioned markets also utilize for-hire mobility setups where fleet operators lease vehicles to independent contract drivers, thereby ensuring profit generation independent of capacity utilization $(20,21)$.
} 
Nunes, A, \& Hernandez, K.D. (2020). Autonomous taxis and public health: High cost of high opportunity cost? Transportation Research Part A: Policy and Practice. Vol 138, 28 - 36.

\section{References}

1. Baum, C. L. (2009). The Effects of Vehicle Ownership on Employment. Journal of Urban Economics, Vol 66(3): 151-63.

2. United States Environmental Protection Agency (2018). Fast Facts: U.S. Transportation Sector Greenhouse Gas Emissions 1990 -2016, United States Environmental Protection Agency, Office of Transportation and Air Quality EPA-420-F-18-013.

3. Hoek, G., Brunekreef, B., Goldbohm, R. A., Fischer, P., \& van den Brandt, P. A. (2002). Association between mortality and indicators of traffic-related air pollution in the Netherlands: a cohort study. Lancet, 360 (9341), 1203-1209.

4. World Health Organization (2005). Health effects of transport-related air pollution. Copenhagen: WHO Regional Office for Europe; pp. 125-65

5. Gen, B \& Barrett, W (2018). Clean air future: Health and climate benefits of zero emission vehicles. American Lung Association. Retrieved from: http://www.lung.org/localcontent/california/documents/2016zeroemissions.pdf

6. Kalra, N, \& Groves, D.G. (2017). The Enemy of Good: Estimating the Cost of Waiting for Nearly Perfect Automated Vehicles. Santa Monica, CA: RAND Corporation, 2017. https://www.rand.org/pubs/research_reports/RR2150.html.

7. Fagnant D, Kockelman K (2015) Preparing a nation for autonomous vehicles: opportunities, barriers and policy recommendations, Transportation Research Part A: Policy and Practice, 77: pp: $167-181$.

8. Barth, M \& Boriboonsomsin, K (2009). Energy and emissions impacts of a freeway-based dynamic eco-driving system. Transportation Research: Part D, Vol 14 (6), pp. $400-410$.

9. Wadud, Z, MacKenzie, D and Leiby, P (2016). Help or hindrance? The travel, energy and carbon impact of highly automated vehicles. Transportation Research Part A: Policy and Practice, doi:10.1016/j

10. Greenblatt, J. B. \& Saxena, S (2015). Autonomous taxis could greatly reduce greenhouse-gas emissions of US light-duty vehicles, Nature Climate Change, Vol 5, 804-805.

11.Savage, I. (2013). Reflections on the economics of transportation safety. Research in Transportation Economics: 43 (1), pp. 1-8.

12. National Highway Traffic Safety Administration (2015). Critical Reasons for Crashes Investigated in the National Motor Vehicle Crash Causation Survey, Washington, D.C.: U.S. Department of Transportation, DOT HS 812 115, February 2015. As of September 12, 2017: https://crashstats.nhtsa.dot.gov/Api/Public/ViewPublication/812115 
Nunes, A, \& Hernandez, K.D. (2020). Autonomous taxis and public health: High cost of high opportunity cost? Transportation Research Part A: Policy and Practice. Vol 138, 28 - 36.

13. Lewis P, Rogers G, Turner S (2017) Beyond Speculation: Automated Vehicles and Public Policy, Eno Center for Transportation, Retrieved from https://www.enotrans.org/wpcontent/uploads/2017/04/AV_FINAL.pdf

14. Mosquet, X, Anderson, M, \& Arora A (2017). A roadmap to safer driving through advanced driver assistance systems, The Boston Consulting Group for the Motor and Equipment Manufacturer's Association, Retrieved from http://image-src.bcg.com/Images/MEMA-BCG-ARoadmap-to-Safer-Driving-Sep-2015 tcm9-63787.pdf

15. Levy, J.I., Buonocore, J.J. \& von Stackelberg, K. (2010). Evaluation of the public health impacts of traffic congestion: a health risk assessment. Environ Health 9, 65 doi:10.1186/1476069X-9-65

16. UBS Global Research (2017). How disruptive will a mass adoption of robotaxis be?, UBS Global Research, Q Series, As of Aug 10, 2018: Retrieved from https://neo.ubs.com/shared/d1gAiLhfW3FA/

17. Bösch, P. M., Becker, F., Becker, H., \& Axhausen, K. W. (2018). Cost-based analysis of autonomous mobility services. Transport Policy, 64, 76-91.

18. Compostella, J, Fultin, L.M, Kliene, R.D., Kim, H, C, \& Wallington, T.J (2020). Near- (2020) and long-term (2030-2035) costs of automated, electrified, and shared mobility in the United States, Transport Policy, 85, 54-66.

19. Nunes, A, Reimer, B, \& Coughlin, J. (2018). Humans must retain control of autonomous vehicles. Nature, Vol 556, $169-172$.

20. Higgins, T (2018). Driverless Cars Still Handled by Humans - From Afar. The Wall Street Journal, June 5.

21. Cooper, J., Mundy, R., \& Nelson, J. (2010). Taxi!: urban economies and the social and transport impacts of the taxicab: Ashgate Publishing, Ltd.

22. Zhang, Y (2014). How Do Taxis Work in Beijing? An Exploratory Study of Spatio-Temporal Taxi Travel Pattern Using GPS Data. UCLA. ProQuest ID: ZHANG_ucla_0031N_12486. Merritt ID: ark:/13030/m5s19gqg. Retrieved from https://escholarship.org/uc/item/91x5p080

23. Cramer, J \& Krueger, A.B. (2016) Disruptive Change in the Taxi Business: The Case of Uber." American Economic Review, 106 (5): 177-82.14.

24. Fehr \& Peers (2019). Estimated TNC Share of VMT in Six US Metropolitan Regions, Fehr \& Peers Report, SF19-1016. Available at https://www.fehrandpeers.com/what-are-tncs-share-ofvmt/

25. Narayanan, S., Chaniotakis, E., \& Antoniou, C. (2020). Shared autonomous vehicle services: A comprehensive review. Transportation Research Part C: Emerging Technologies, 111, 255-293.

26. Colias, M \& Sommerville, H (2019). Cruise, GM's Driverless-Car Unit, Delays Robot-Taxi Service, Wall Street Journal. Jul 24. 
Nunes, A, \& Hernandez, K.D. (2020). Autonomous taxis and public health: High cost of high opportunity cost? Transportation Research Part A: Policy and Practice. Vol 138, 28 - 36.

27. Colias, M. (2018). GM Aims for Self-Driving Taxi Fleet by 2019, Wall Street Journal. Nov 30 .

28. Fulton, L, Mason, J and Meroux, D (2017). Three revolutions in urban transportation, Institute for transportation and development policy, University of California at Davis.

29. U.S. Department of Transportation (2018). Summary of Travel Trends - National Household Travel Survey 2017, Federal Highway Administration, U.S. Department of Transportation, Report No: FHWA-PL-18-019.

30. Schwieterman, J.P. \& Michel, M. (2016). Have App Will Travel: Comparing the Price and Speed of Fifty CTA and UberPool Trips in Chicago. Chaddick Institute for Metropolitan Development, Depaul University, Policy Series.

31. Metropolitan Area Planning Council (2018). Fare choices: A survey of ride-hailing passengers in metro Boston, Metropolitan Area Planning Council Research Brief, February 2018. Retrieved from: http://www.mapc.org/wp-content/uploads/2018/02/Fare-Choices-MAPC.pdf

32. Sarriera, J.M., Blynn, K. \& Zhao, J. (2017). To Share or Not To Share: Investigating the Social Aspects of Dynamic, Transportation Research Record: Journal of the Transportation Research Board.

33. California Air Resources Board (2019). SB 2014 Clean Miles Standard 2018 Base-year Emissions Inventory Report, California Air Resources Board.

34. American Automobile Association (2016). American Driving Survey 2014-2015, AAA Foundation for Traffic Safety, Washington, DC.

35. Frederick, S., Novemsky, N., Wang, J., Dhar, R., \& Nowlis, S. (2009). Opportunity cost neglect. Journal of Consumer Research, 36, 553-561. https://doi.org/10.1086/599764.

36. Kahneman, D \& Frederick, S (2002), "Representativeness Revisited: Attribute Substitution in Intuitive Judgment," in Heuristics and Biases: The Psychology of Intuitive Judgment, ed. Thomas Gilovich, Dale Griffin, and Daniel Kahneman, New York: Cambridge University Press, 48-81.

37. Bonnefon J-F, Shariff A, Rahwan, I (2016) The Social Dilemma of Autonomous Vehicles. Science 24 (352), pp. 1573-1576.

38. Kerry, C.F. \& Karsten, J (2017). Gauging investment in self-driving cars. The Brookings Institution, Report retrieved from https://www.brookings.edu/research/gauging-investment-inself-driving-cars/

39. Center for Connected \& Autonomous Vehicles (2018). UK Connected \& Autonomous Vehicle Research \& Development Projects 2018, Department of Transport / Department of Business, Energy \& Industrial Strategy, Retrieved from https://assets.publishing.service.gov.uk/government/uploads/system/uploads/attachment_data/file 7737778/ccav-research-and-development-projects.pdf 
Nunes, A, \& Hernandez, K.D. (2020). Autonomous taxis and public health: High cost of high opportunity cost? Transportation Research Part A: Policy and Practice. Vol 138, 28 - 36.

40. United States Department of Transportation (2019). Automated Vehicle Research, U.S. Department of Transportation, Retrieved from https:/www.transportation.gov/av/research.

41. Luttrell, K, Weaver, M, \& Harris, M (2015)._The effect of autonomous vehicles on trauma and health care, The Journal of Trauma and Acute Care Surgery, Oct; Vol 79(4):678-82

42. Small, K., \& Verhoef, E. T. (2007). The Economics of Urban Transportation. London: Routledge.

43. Eno Center for Transportation (2013). Preparing a Nation for Autonomous Vehicles: Opportunities, Barriers and Policy Recommendations. Retrieved from https://www.enotrans.org/wp-content/uploads/wpsc/downloadables/AV- paper.pdf.

44. AT Kearney (2016). How automakers can survive the self-driving era, A.T. Kearney, Inc, Retrieved from https://www.atkearney.com/documents/10192/8591837/How +Automakers + Can + Survive + the + S elf-Driving+Era+\%282\%29.pdf/1674f48b-9da0-45e8-a970-0dfbd744cc2f

45. Reid, J., \& Chanda, S (2017). Mapping the world's prices, Deutsche Bank Market Research, Deutsche Bank AG/London. Retrieved from: https:/www.finews.ch/images/download/Mapping.the.worlds.prices.2017.pdf

46. Land Transport Authority (2015). Factsheet, More taxis plying the roads for commuters in 2015, Singapore Government, Land Transport Authority, Retrieved from https://www.lta.gov.sg/apps/news/page.aspx?c=2\&id=766364af-eb2f-4d2a-9575-1499d862777f 
Nunes, A, \& Hernandez, K.D. (2020). Autonomous taxis and public health: High cost of high opportunity cost? Transportation Research Part A: Policy and Practice. Vol 138, 28 - 36.

\section{Acknowledgements}

This work was partially supported by the MIT Energy Initiative's Mobility of the Future study.

The views expressed are those of the authors and do not necessarily represent those of the funding organization.

The authors declare no potential conflict of interest. 


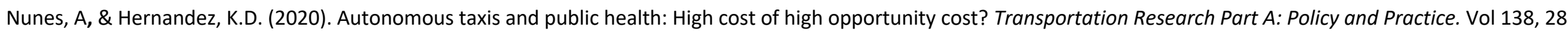
-36 .

\section{Figures and Tables}

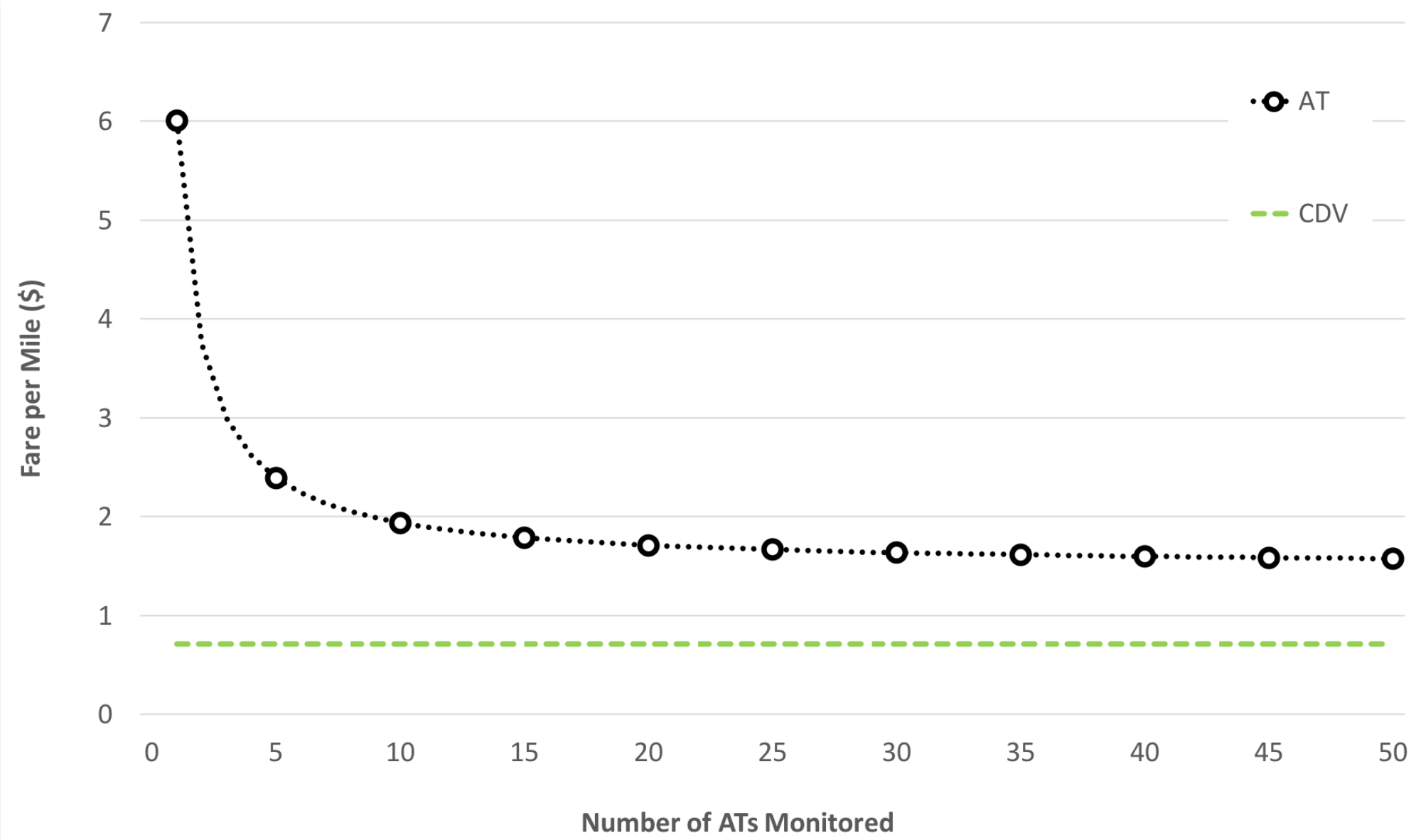

Figure 1a: AT versus CDV Cost Comparison 
Nunes, A, \& Hernandez, K.D. (2020). Autonomous taxis and public health: High cost of high opportunity cost? Transportation Research Part A: Policy and Practice. Vol 138, $28-36$.

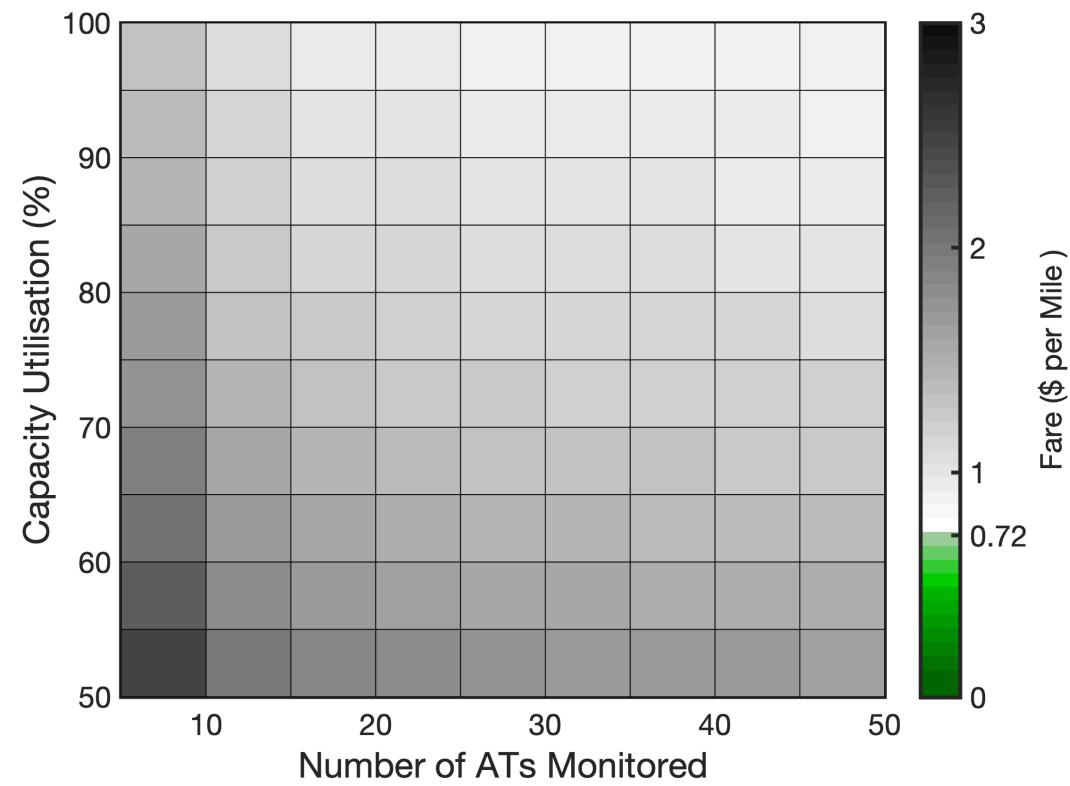

Fig. 1b

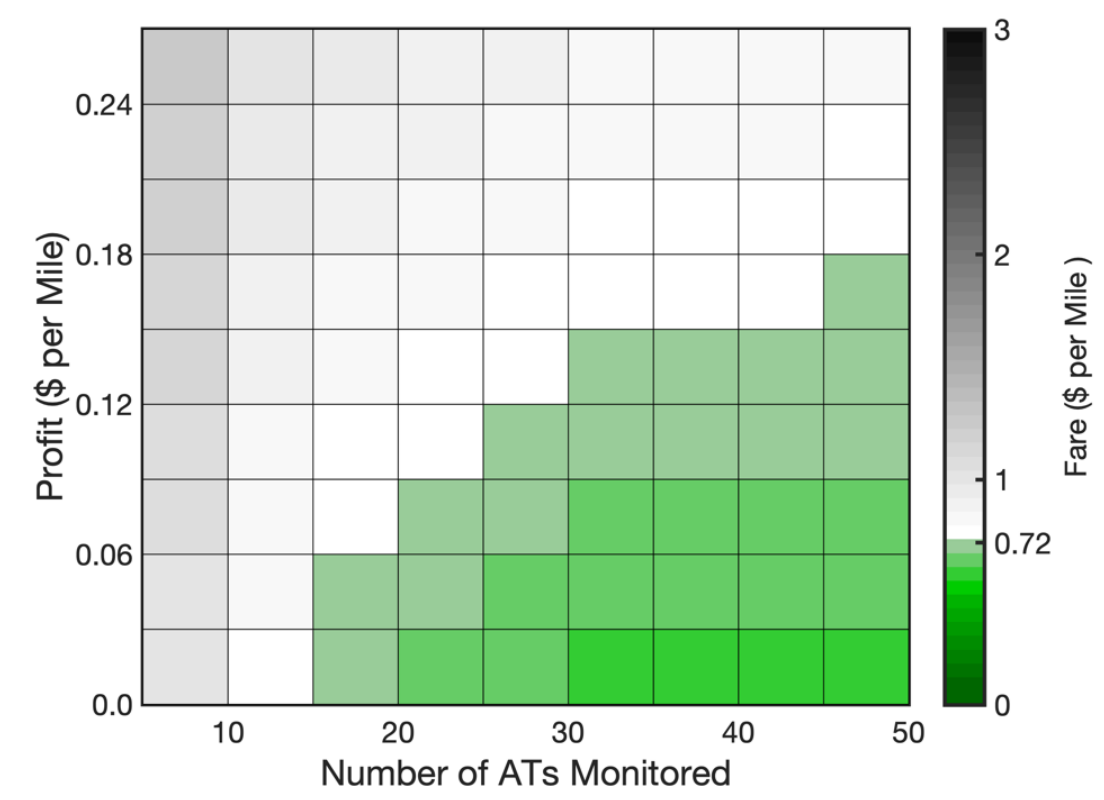

Fig. 1c

Figures 1b-c: AT fare per mile estimates assuming increasing capacity utilization with profit held constant (\$0.27) (1b), and capacity utilization maximization (100\%) with decreasing profit expectations (i.e., lower than \$0.27) (1c). Green shades represent cost competitiveness with CDVs. 
Nunes, A, \& Hernandez, K.D. (2020). Autonomous taxis and public health: High cost of high opportunity cost? Transportation Research Part A: Policy and Practice. Vol 138, $28-36$.

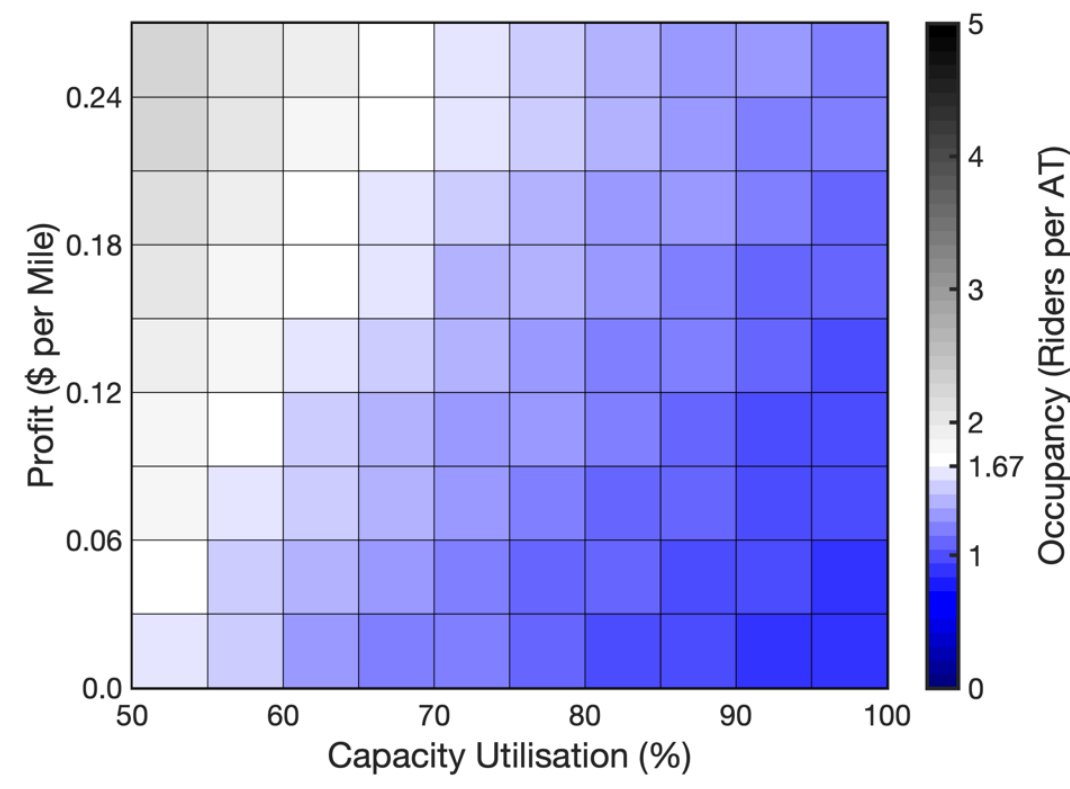

Fig. 2a

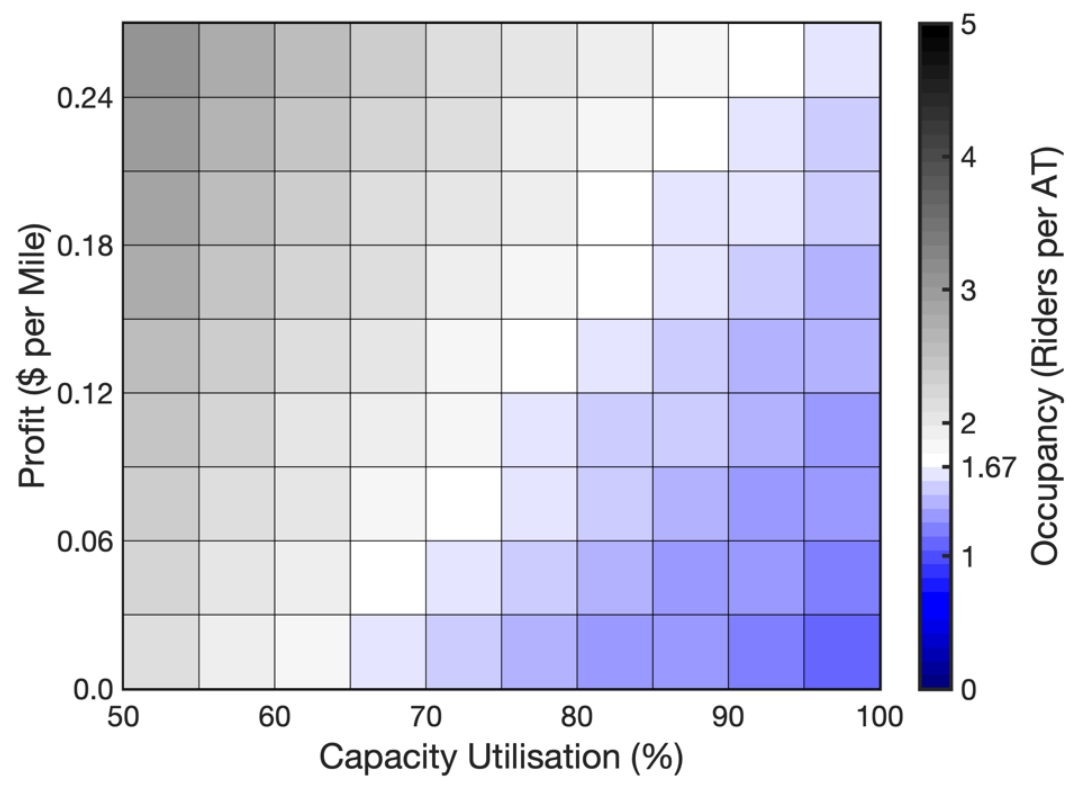

Fig. 2b

Figures 2a-b: AT occupancy requirement assuming an equivalent (2a) and lower (2b) AT fare per mile expenditures compared to CDVs. Blue shades represent cost parity at current ridership levels 
Nunes, A, \& Hernandez, K.D. (2020). Autonomous taxis and public health: High cost of high opportunity cost? Transportation Research Part A: Policy and Practice. Vol 138, $28-36$.

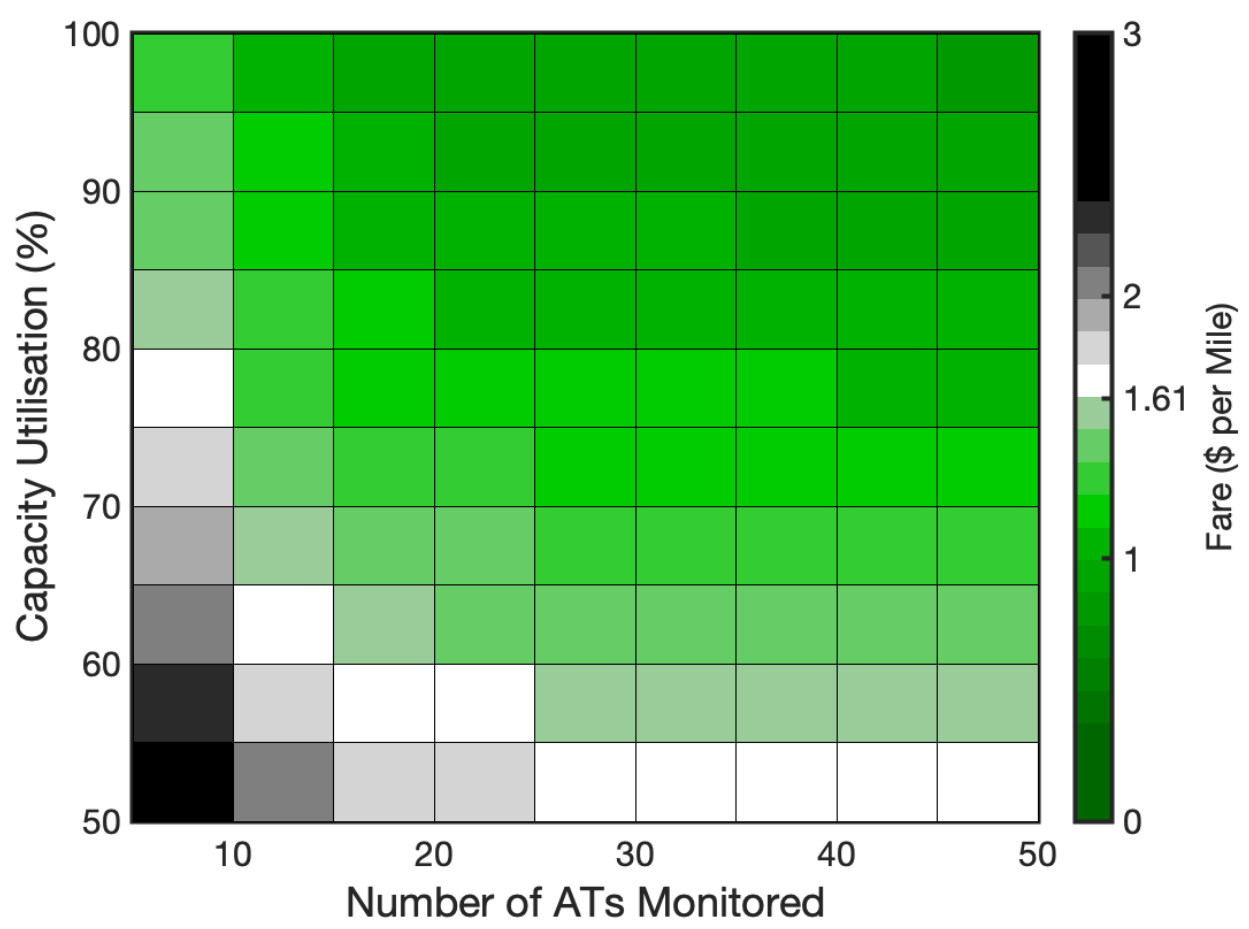

Figures 3a: AT fare per mile estimates assuming increasing capacity utilization (with profit held constant at \$0.27) and consideration of opportunity costs of CDV ownership. Green shades represent cost competitiveness with CDVs. 
Nunes, A, \& Hernandez, K.D. (2020). Autonomous taxis and public health: High cost of high opportunity cost? Transportation Research Part A: Policy and Practice. Vol 138, 28 - 36.

\begin{tabular}{|c|c|c|}
\cline { 2 - 3 } \multicolumn{1}{c|}{} & CDV & AT \\
\hline Vehicle Financing & $\$ 0.25$ & $\$ 0.04$ \\
\hline Licensing & $\$ 0.003$ & $\$ 0.16$ \\
\hline Insurance & $\$ 0.19$ & $\$ 0.11$ \\
\hline Maintenance & $\$ 0.12$ & $\$ 0.08$ \\
\hline Cleaning & $\$ 0.02$ & $\$ 0.05$ \\
\hline Fuel & $\$ 0.12$ & $\$ 0.07$ \\
\hline Parking & $\$ 0.01$ & n.a. \\
\hline Safety Oversight & n.a. & $\$ 0.05-\$ 2.35$ \\
\hline Profit & n.a. & $\$ 0.27$ \\
\hline Total Cost & $\$ 0.72$ & $\$ 1.58-\$ 6.01$ \\
\hline
\end{tabular}

CDV costs exclude time valuation. AT Fares are adjusted to reflect capacity utilization rates (estimated to be $52 \%$ ). For more detail on estimate assumptions and computation methods, see Supplementary Information section.

Table 1: Per Mile Estimation of CDV ownership costs and AT Fares 
Nunes, A, \& Hernandez, K.D. (2020). Autonomous taxis and public health: High cost of high opportunity cost? Transportation Research Part A: Policy and Practice. Vol 138, $28-36$.

\section{Number of ATs Monitored}

\begin{tabular}{|c|c|c|c|c|c|c|c|c|c|c|}
\hline & 5 & 10 & 15 & 20 & 25 & 30 & 35 & 40 & 45 & 50 \\
\hline \multirow[t]{2}{*}{ Financing } & 0.004 & 0.004 & 0.004 & 0.004 & 0.004 & 0.004 & 0.004 & 0.004 & 0.004 & 0.004 \\
\hline & -0.149 & -0.184 & -0.199 & -0.208 & -0.214 & -0.218 & -0.221 & -0.223 & -0.225 & -0.226 \\
\hline \multirow[t]{2}{*}{ Licensing } & 0.015 & 0.015 & 0.015 & 0.015 & 0.015 & 0.015 & 0.015 & 0.015 & 0.015 & 0.015 \\
\hline & -0.640 & -0.789 & -0.856 & -0.893 & -0.917 & -0.934 & -0.947 & -0.956 & -0.964 & -0.970 \\
\hline \multirow[t]{2}{*}{ Insurance } & 0.010 & 0.010 & 0.010 & 0.010 & 0.010 & 0.010 & 0.010 & 0.010 & 0.010 & 0.010 \\
\hline & -0.429 & -0.529 & -0.574 & -0.599 & -0.615 & -0.627 & -0.635 & -0.641 & -0.646 & -0.651 \\
\hline \multirow[t]{2}{*}{ Maintenance } & 0.008 & 0.008 & 0.008 & 0.008 & 0.008 & 0.008 & 0.008 & 0.008 & 0.008 & 0.008 \\
\hline & -0.318 & -0.392 & -0.425 & -0.444 & -0.456 & -0.464 & -0.470 & -0.475 & -0.479 & -0.482 \\
\hline \multirow[t]{2}{*}{ Cleaning } & 0.005 & 0.005 & 0.005 & 0.005 & 0.005 & 0.005 & 0.005 & 0.005 & 0.005 & 0.005 \\
\hline & -0.202 & -0.249 & -0.270 & -0.282 & -0.290 & -0.295 & -0.299 & -0.302 & -0.304 & -0.306 \\
\hline \multirow[t]{2}{*}{ Fuel } & 0.007 & 0.007 & 0.007 & 0.007 & 0.007 & 0.007 & 0.007 & 0.007 & 0.007 & 0.007 \\
\hline & -0.282 & -0.348 & -0.377 & -0.393 & -0.404 & -0.412 & -0.417 & -0.421 & -0.425 & -0.427 \\
\hline \multirow[t]{2}{*}{ Safety Oversight } & 0.045 & 0.023 & 0.015 & 0.011 & 0.009 & 0.008 & 0.006 & 0.006 & 0.005 & 0.005 \\
\hline & -1.892 & -1.167 & -0.843 & -0.660 & -0.543 & -0.461 & -0.400 & -0.354 & -0.317 & -0.287 \\
\hline \multirow[t]{2}{*}{ Profit } & 0.026 & 0.026 & 0.026 & 0.026 & 0.026 & 0.026 & 0.026 & 0.026 & 0.026 & 0.026 \\
\hline & -1.089 & -1.343 & -1.456 & -1.520 & -1.561 & -1.590 & -1.611 & -1.628 & -1.641 & -1.651 \\
\hline \multirow[t]{2}{*}{ Capacity Utilization } & 0.114 & 0.092 & 0.085 & 0.082 & 0.079 & 0.078 & 0.077 & 0.076 & 0.076 & 0.075 \\
\hline & -4.762 & -4.762 & -4.762 & -4.762 & -4.762 & -4.762 & -4.762 & -4.762 & -4.762 & -4.762 \\
\hline
\end{tabular}

For each input parameters, the upper line denotes the absolute change in fare-per-mile (\$) whereas the lower line, the relative change (\%). With the exception of capacity utilization, directionality of all input parameters is negative

Table 2: AT Fare per mile elasticity given a $5 \%$ change in specified parameters 
Nunes, A, \& Hernandez, K.D. (2020). Autonomous taxis and public health: High cost of high opportunity cost? Transportation Research Part A: Policy and Practice. Vol 138, 28 - 36.

\section{Supplementary Information Appendix}

\section{Detailed Cost Estimate Computation}

Cost estimates and applicable operating parameters are derived for existing for-hire service operators (i.e., taxis), ATs and CDVs.

Ensuing fare/cost-per-mile estimates are, absent considerations of licensure, supervisory monitoring, profit and capacity utilization, consistent with existing literature/analysis. Consequently, a key contribution of our work is identifying the role the aforementioned variables play in affecting the cost proposition of ATs.

An important objective in presenting our methodology and analysis is to ensure transparency and usability by other researchers. Consequently, all AT and non-AT related cost estimates and operating parameters are ascertained using public data. References supporting our estimates are separately presented at the end of this document. 
Nunes, A, \& Hernandez, K.D. (2020). Autonomous taxis and public health: High cost of high opportunity cost? Transportation Research Part A: Policy and Practice. Vol 138, 28 - 36.

\section{SUPPLEMENTARY DATA}

\section{Existing For-Hire (Taxi) Cost Estimation}

\begin{tabular}{|c|c|}
\cline { 2 - 2 } \multicolumn{1}{c|}{} & Assumption \\
\hline Current Fare per Mile & $\$ 3.55^{\mathrm{a}}$ \\
\hline Capacity Utilization Rate & $52 \% \mathrm{~b}$ \\
\hline Vehicle Cost & $\$ 15,000^{\mathrm{c}}$ \\
\hline Fleet Operator Profit per Mile & $\$ 0.27^{\mathrm{d}}$ \\
\hline Annual Mileage & $90,000^{\mathrm{e}}$ \\
\hline Taxi Driver Shift Length & 12 hours $^{\mathrm{f}}$ \\
\hline Lifespan of Vehicle & 5 years $^{\mathrm{g}}$ \\
\hline Powertrain & Hybrid $^{\mathrm{h}}$ \\
\hline
\end{tabular}

a A taxi fare in San Francisco is currently $\$ 3.50$ for the first 0.2 miles or "flag," $\$ 0.55$ for each additional 0.2 miles, and $\$ 0.55$ for each minute of waiting or traffic delay time. The average taxi trip length in San Francisco is 3.7 miles. Ignoring the cost of traffic delay, the fare for such a trip would be $\$ 3.50+((3.7-0.2) / 0.2) \times(0.55)=\$ 3.50+\$ 9.62=\$ 13.12$. On average, this amounts to $\$ 13.12$ over 3.7 miles $=\$ 3.55$ per mile $(1,2)$.

b Taxis in San Francisco average 4.02 passenger miles to 3.70 unoccupied miles traveled. $(4.02) /(4.02+3.70)=0.52(1)$. Alternative sources indicate target market capacity utilization rates that are roughly consistent with or lower than the aforementioned estimate $(3,4)$.

${ }^{c}$ Value derived from PFM Group Consulting \& Schaller Consulting (5).

${ }^{d}$ Profit per mile represents the current profit generated on a per mile basis by current for-hire (taxi) fleet operators in San Francisco. These companies levy a gate fee on drivers for using company vehicles. The gate fee is currently capped at $\$ 106.25$ per shift for a shift of 10 hours or longer. Assuming a taxi travels 90,000 miles per year, this amounts to 250 miles per day. Assuming two work shifts daily, this means each shift entails covering a distance of 125 miles. This amounts to $\$ 0.85$ per mile (\$106.25/125 miles). Taxi fleet operators are currently responsible for paying for the vehicle, medallion, insurance, maintenance, cleaning costs, G\&A, and dispatchers. G\&A costs are assumed to be about $\$ 0.05$ per mile (2). 
For estimated dispatcher cost, data is leveraged from the Bureau of Labor Statistics on the number of dispatchers in the San Francisco area. In the San Francisco-Oakland-Hayward area, there are 3,780 "Dispatchers, Except Police, Fire, and Ambulance" and in the San FranciscoRedwood City-South San Francisco area, 1,920 "Dispatchers, Except Police, Fire, and Ambulance." Nationwide, taxi \& limo dispatchers make up about 5\% (9,690/198,520) of "Dispatchers, Except Police, Fire, and Ambulance." Assuming a constant industry-wide percentage is reflected nationwide, this means there are 181 taxi dispatchers in the San Francisco-Oakland-Hayward area and 92 taxi dispatchers in the San Francisco-Redwood City-South San Francisco area.

Given there are 1,785 taxis currently operating in San Francisco, this is between 10 and 20 taxis per dispatcher. Assume local dispatchers earn a base salary of $\$ 51,328$ per year with no benefits and monitor half of the mileage of 10 taxis, this amount to $(\$ 51,328 / 450,000$ miles $) \$ 0.11$ per mile (6-10). Cleaning costs are also assumed to be lower in a CDV as there are no sensors that require regular cleaning. We use $2 \mathrm{CHF} / 100 \mathrm{~km}$ instead of 3 , which gives us $(2 \mathrm{CHF} / 100 \mathrm{~km}) \times$ $(1 \mathrm{~km} / 0.621371 \mathrm{miles}) \times(\$ 1.04 / 1 \mathrm{CHF})=\$ 0.03$ per mile $(11)$. Thus, current fleet operator profit per mile in a CDV is $\$ 0.27$ per mile $(\$ 0.85-(\$ 0.11+\$ 0.05+\$ 0.03+\$ 0.08+\$ 0.11+\$ 0.16+$ \$0.04)).

e Value derived from Green Car Reports (12).

${ }^{\mathrm{f}}$ A taxi driver shift length of 12 hours (13).

g A taxi in San Francisco is currently allowed to reach a maximum of 425,000 miles, which has been rounded up to about 5 years (2).

${ }^{\mathrm{h}}$ Powertrain choice is based on existing information (14). 
Nunes, A, \& Hernandez, K.D. (2020). Autonomous taxis and public health: High cost of high opportunity cost? Transportation Research Part A: Policy and Practice. Vol 138, 28 - 36.

AT Fare Estimation

\begin{tabular}{|c|c|c|}
\cline { 2 - 3 } \multicolumn{1}{c|}{} & Total Cost & Cost per Mile \\
\hline Vehicle Financing & $\$ 15,000$ & $\$ 0.04^{\mathrm{i}}$ \\
\hline Licensing & $\$ 250,000$ & $\$ 0.16^{\mathrm{j}}$ \\
\hline Insurance & $\$ 9,600$ p.a. & $\$ 0.11^{\mathrm{k}}$ \\
\hline Maintenance & $\$ 7,110$ p.a. & $\$ 0.08^{\mathrm{1}}$ \\
\hline Cleaning & $\$ 4,520$ p.a. & $\$ 0.05^{\mathrm{m}}$ \\
\hline Fuel & $\$ 6,305$ p.a. & $\$ 0.07^{\mathrm{n}}$ \\
\hline Safety Oversight & $\$ 211,662$ p.a. & $\$ 0.05-\$ 2.35^{\circ}$ \\
\hline Profit & $\$ 24,363$ p.a. & $\$ 0.27^{\mathrm{p}}$ \\
\hline Fare & n.a. & $\$ 1.58-\$ 6.01^{\mathrm{q}}$ \\
\hline
\end{tabular}

I Vehicle price is $\$ 15,000$. In addition to no down payment being applied, the annual interest rate is set at $7 \%$ and the loan is paid off over three years. Monthly loan payments follow Amount / Discount Factor

$$
\text { Discount Factor }=\left\{\left[(1+i)^{n}\right]-1\right\} \div\left[i(1+i)^{n}\right]
$$

Where $\mathrm{n}=$ payments per year multiplied by the number of years and $\mathrm{I}=$ annual interest rate divided by number of payment periods.

$$
\text { Loan Payment }=\frac{15,000}{\left(\left(\left(1+\left(\frac{0.07}{12}\right)\right)^{36}\right)-1\right) \div\left(\left(\frac{0.07}{12}\right)\left(1+\left(\frac{0.07}{12}\right)\right)^{36}\right)}
$$

This amounts to $\$ 463.16$ monthly for 36 months, yielding a cumulative vehicle cost of $\$ 16,673.63$. Assuming a vehicle lifespan of 5 years and annual mileage of 90,000, this averages to $\$ 16,673.63 /(90,000 \times 5)=\$ 0.04$ per mile $(5)$.

j A medallion costs $\$ 250,000$ in San Francisco. A down payment of 20\% $(\$ 50,000)$ is applied with $25 \%(\$ 12,500)$ paid up front. The initial balance $(\$ 37,500)$ is financed over 7 years at $5.40 \%$ 
Nunes, A, \& Hernandez, K.D. (2020). Autonomous taxis and public health: High cost of high opportunity cost? Transportation Research Part A: Policy and Practice. Vol 138, 28 - 36.

interest. The cumulative balance $(\$ 200,000)$ is financed over 5 years at $5.40 \%$ interest. Monthly loan payments follow Amount / Discount Factor

$$
\text { Discount Factor }=\left\{\left[(1+i)^{n}\right]-1\right\} \div\left[i(1+i)^{n}\right]
$$

Where $\mathrm{n}=$ payments per year multiplied by the number of years and $\mathrm{I}=$ annual interest rate divided by number of payment periods. For financing of the initial balance,

$$
\text { Loan Payment }=\frac{37,500}{\left(\left(\left(1+\left(\frac{0.054}{12}\right)\right)^{84}\right)-1\right) \div\left(\left(\frac{0.054}{12}\right)\left(1+\left(\frac{0.054}{12}\right)\right)^{84}\right)}
$$

This amounts to $\$ 537.10$ per month for 84 months, yielding a total $\$ 45,116.27$. For the cumulative balance $(\$ 200,000)$,

$$
\text { Loan Payment }=\frac{200,000}{\left(\left(\left(1+\left(\frac{0.054}{12}\right)\right)^{60}\right)-1\right) \div\left(\left(\frac{0.054}{12}\right)\left(1+\left(\frac{0.054}{12}\right)\right)^{60}\right)}
$$

This amounts to $\$ 3,811.01$ per month for 60 months, yielding a total of $\$ 228,660.47$. Assuming a medallion lifespan of 20 years and annual mileage is 90,000 , this amounts to $(\$ 12,500+$ $\$ 45,116.27+\$ 228,660.47) /(90,000 \times 20)=\$ 0.16$ per mile $(5)$.

${ }^{\mathrm{k}}$ A monthly insurance premium of $\$ 800$ is assumed, which generates an annual cost of $\$ 9,600$. Assuming an annual mileage of 90,000 , this amounts to $\$ 0.11$ per mile (5).

${ }^{1}$ Value derived from United States Bureau of Transportation Statistics (15).

m Bösch, et al. 2017 propose a cleaning cost of $3 \mathrm{CHF} / 100 \mathrm{~km}$ for a midsize autonomous vehicle. Using a conversion rate of 0.621371 miles per kilometer and $\$ 1.04$ per CHF, we calculate a cleaning cost of $(3 \mathrm{CHF} / 100 \mathrm{~km}) \times(1 \mathrm{~km} / 0.621371 \mathrm{miles}) \times(\$ 1.04 / 1 \mathrm{CHF})=\$ 0.05$ per mile $(11)$.

${ }^{\mathrm{n}}$ Gas mileage is assumed to be $43 \mathrm{mpg}$ and the average price of gas per gallon, $\$ 3.01$. Assuming an annual mileage of $90,000 \mathrm{~m}$ average fuel cost amounts to $((90,000 / 43) \times 3.012481) / 90,000=$ $\$ 0.07$ per mile $(16,17)$.

${ }^{\circ}$ Supervisory monitors providing safety oversight are assumed to be hourly workers who are paid minimum wage. In California, this is $\$ 11$ /hour. Supervisory monitors are - in the interests of minimizing operating costs - assumed to receive no benefits. A fifty 'cluster' maximum is set, this nearly double that seen in comparable professions such as air traffic control. Given the safety critical nature of the work and consistent with other supervisory control setups across the finance, energy and transportation sector, two supervisory monitors are required per AT cluster per 12-hour shift amounting to four supervisory monitors per cluster per day.

One group of supervisory monitors works 5 days a week, 50 weeks per year (a total of 250 days per year). Another group of supervisory monitors works weekends plus the additional two 
Nunes, A, \& Hernandez, K.D. (2020). Autonomous taxis and public health: High cost of high opportunity cost? Transportation Research Part A: Policy and Practice. Vol 138, 28 - 36.

weeks the first group does not work (a total of 114 days per year). The overhead rate (set at 1.59) accounts for costs such as office space, equipment, and utilities and therefore is only applicable to one of the eight supervisory monitors that is responsible for a AT cluster (as the others would be utilizing the same resources).

Thus, annual supervisory monitor salary for a single AT cluster is $((250 \times 12 \times 11) \times 1.59 \times 1)$ $+((250 \times 12 \times 11) \times 3)+((114 \times 12 \times 11) \times 4)=\$ 211,662$. The cost per mile attributed solely to teleoperation will vary by the number of ATs contained in a cluster. If one supervisory monitor watches one AT, the per mile cost is $\$ 2.35(\$ 211,662 / 90,000)$. However, if 50 ATs are monitored by a supervisory monitor, the per mile cost drops to $\$ 0.05(\$ 211,662 /(90,000 \times 50)(18)$. A drop these costs from $\$ 211,662$ to $\sim \$ 100,000$ assumes a single operator working per AT cluster for a 12-hour shift amounting to two supervisory monitors per cluster per 24 hours.

${ }^{\mathrm{p}}$ Profit per mile in the AT scenario is assumed to be the same as the profit per mile estimates realized by fleet operators today.

${ }^{\mathrm{q}}$ The fare per mile is adjusted for the capacity utilization rate of the AT (considered for our analysis to be analogous to the existing for-hire vehicle industry (i.e., 52\%)). This was calculated using the following equation:

Fare per Mile $=\frac{\text { Financing }+ \text { Licensing }+ \text { Insurance }+ \text { Maintenance }+ \text { Cleaning }+ \text { Fuel }+ \text { Safety Oversight }+ \text { Profit }}{\text { Capacity Utilization Rate }}$

where Financing, Licensing, Insurance, Maintenance, Cleaning, Fuel, Safety Oversight and Profit are all per mile costs. 
Nunes, A, \& Hernandez, K.D. (2020). Autonomous taxis and public health: High cost of high opportunity cost? Transportation Research Part A: Policy and Practice. Vol 138, 28-36.

\section{Ownership Cost Estimation (New Vehicle)}

\begin{tabular}{|c|c|c|}
\cline { 2 - 3 } \multicolumn{1}{c|}{} & Total Cost & Cost per Mile \\
\hline Vehicle Financing & $\$ 36,113$ & $\$ 0.25^{\mathrm{r}}$ \\
\hline Licensing & $\$ 29$ per year & $\$ 0.003^{\mathrm{s}}$ \\
\hline Insurance & $\$ 1,962$ per year & $\$ 0.19^{\mathrm{t}}$ \\
\hline Maintenance & $\$ 1,186$ per year & $\$ 0.12^{\mathrm{u}}$ \\
\hline Cleaning & $\$ 206$ per year & $\$ 0.02^{\mathrm{v}}$ \\
\hline Fuel & $\$ 1,241$ per year & $\$ 0.12^{\mathrm{w}}$ \\
\hline Parking & $\$ 136$ per year & $\$ 0.01^{\mathrm{x}}$ \\
\hline Total Ownership Cost & n.a. & $\$ 0.72^{\mathrm{y}}$ \\
\hline Value of Time & $\$ 9,137$ per year & $\$ 0.89^{\mathrm{z}}$ \\
\hline Total Cost (including value of time) & n.a. & $\$ 1.61$ \\
\hline
\end{tabular}

${ }^{\mathrm{r}}$ Average purchase price of a vehicle in 2017 was $\$ 36,113$. Assuming a 20\% down payment and an interest rate of $4.21 \%$, the loan is paid off over five years. Monthly loan payments follow Amount / Discount Factor

$$
\text { Discount Factor }=\left\{\left[(1+i)^{n}\right]-1\right\} \div\left[i(1+i)^{n}\right]
$$

Where $n=$ payments per year times number of years and $\mathrm{i}=$ annual interest rate divided by number of payment periods.

$$
\text { Loan Payment }=\frac{28,890.40}{\left(\left(\left(1+\left(\frac{0.0421}{12}\right)\right)^{60}\right)-1\right) \div\left(\left(\frac{0.0421}{12}\right)\left(1+\left(\frac{0.0421}{12}\right)\right)^{60}\right)}
$$

The monthly loan payment amounts to $\$ 534.80$ for 60 months. In total, this equals $\$ 32,088.18$. Combined with the initial down payment and assuming a vehicle lifespan of 15 years ${ }^{\text {aa }}$ with an average annual mileage of 10,301 , this amounts to $(\$ 32,088.18+\$ 7,222.60) /(10,301 \times 15)=\$ 0.25$ per mile (19-22). 
Nunes, A, \& Hernandez, K.D. (2020). Autonomous taxis and public health: High cost of high opportunity cost? Transportation Research Part A: Policy and Practice. Vol 138, 28 - 36.

${ }^{\mathrm{s}}$ Vehicle registration has a renewal fee of $\$ 29$ per year. Assuming an annual mileage of 10,301, the registration cost per mile is $\$ 0.003(\$ 29 / 10,301)(23)$.

${ }^{\mathrm{t}}$ Insurance costs are set at $\$ 1,962$ per year. With an annual mileage of 10,301 miles, this amounts to $\$ 0.19$ per mile $(\$ 1,962 / 10,301)(24)$.

"According to AAA, a new vehicle in 2017 cost about \$1,186 per year to maintain and repair. If a vehicle travels 10,301 miles per year on average, this is $(\$ 1,186 / 10,301)=\$ 0.12$ per mile $(25)$.

${ }^{\mathrm{v}}$ Cleaning costs were estimated using several approaches. First, the average cost of a non-premium car wash was estimated to be between $\$ 6.34$ and $\$ 15.01$, generating an average of $\$ 10.67$. A more premium service was found to cost between $\$ 20$ and $\$ 25$, with the average being $\$ 22.50$. Assuming 8 car washes annually, the cumulative expenditure amounts to between $\$ 85.36$ and $\$ 180$ over 10,301 miles, which equals between $\$ 0.008$ - \$0.017 per mile.

We also considered hand-washing a vehicle. The average cost of car wash kits on Amazon ranges between $\$ 20$ to $\$ 30$. Assuming these supplies are available for the lifetime of the vehicle (15 years) and the vehicle travels 10,301 miles annually, this amounts to $\$ 25$ over 154,515 miles, which is about $\$ 0.0001618$ per mile. Soap costs approximately $\$ 15$ for 64 fluid ounces. If 1 ounce per wash is required, then 64 washes can be obtained from a single bottle, which gives the bottle a lifespan of 8 years. This amounts to a cost of $\$ 15$ over 82,408 miles, which equals $\$ 0.00018202$ per mile. Water costs about $\$ 1.16$ per wash. $\$ 1.16 \times 8$ washes per year $=\$ 9.28$ over 10,301 miles or $\$ 0.00090088$ per mile. The time cost associated with washing one's own car must also be considered. U.S. Census Bureau places the median U.S. household income at \$59,039. Assuming washing one's own car takes 1 hour and a person works about 2,080 hours per year, the per mile time cost of washing one's own car amounts to $\$ 0.02((\$ 59,039 / 2,080) \times 8) / 10,301)$.

Based on the aforementioned scenarios, the per-mile cost of a car wash is estimated to be $\$ 0.02$. Over 10,301 miles, this amounts to $\$ 206$ per year $(11,26-31)$.

w The average fuel mileage in a U.S. car was $25 \mathrm{mpg}$ in December 2017. The average gas price in California in 2017 was $\$ 3.01$ per gallon. Assuming an annual mileage of 10,301, a car requires 412.04 gallons of gas $(10,301$ miles/25 miles per gallon). At a cost of $\$ 3.01$ per gallon, the annual gasoline cost is $\$ 1,241.26(412.04 \times \$ 3.012481)$ or $\$ 0.12$ per mile $(\$ 1,241.26 / 10,301)(17,32)$.

${ }^{\mathrm{x}}$ An annual residential parking permit which allows access to an unreserved curbside parking spot in the San Francisco metro area is $\$ 136$. Assuming a vehicle drives 10,301 miles per year, annual parking cost amounts to $\$ 0.01$ per mile $(\$ 136 / 10,301)$ (33). This figure may - assuming demand inelasticity - be higher were consumers to prioritize convenience over cost (i.e., choose more expensive urban parking structures/ underground parking options in premium/central areas) (34).

$\mathrm{y}$ This value is slightly higher than the sum of the listed costs per mile due to rounding.

z The Department of Transportation's guide to calculating value of time traveled recommends that value of time (VOT) be equal to a certain percentage of a person's hourly wage depending on the circumstances of the trip. For personal local travel, VOT is $50 \%$ of hourly wage; for business local 
Nunes, A, \& Hernandez, K.D. (2020). Autonomous taxis and public health: High cost of high opportunity cost? Transportation Research Part A: Policy and Practice. Vol 138, 28 - 36.

travel, VOT is $100 \%$ of hourly wage; and for all vehicle operators, VOT is $100 \%$ of hourly wage. Thus, we use $100 \%$ of hourly wage in our VOT calculation. The VOT uses 2,080 hours as annual number of working hours in its own calculations. According to the U.S. Census Bureau, the median household income in the United States in 2016 was \$59,039, which is roughly the 2016 median individual income in San Francisco. Thus, the value of time for a median income individual is $\$ 59,039 / 2,080$ hours $=\$ 28.38$ per hour. In order to find the value of time per mile, we used average vehicle speed. In the United States, average vehicle speed is 32 miles per hour (the average U.S. driver travels 29 miles per day and drives 55 minutes per day). $\$ 28.38 / 32$ miles $=\$ 0.89$ per mile $(31,34-36)$.

aa Vehicles in the United States have a lifespan of 13 to 17 years, the average of which is 15 years (37). 
Nunes, A, \& Hernandez, K.D. (2020). Autonomous taxis and public health: High cost of high opportunity cost? Transportation Research Part A: Policy and Practice. Vol 138, 28 - 36.

\section{References}

1. Rayle, L., Shaheen, S., Chan, N., Dai, D., \& Cervero, R. (2014, November). App-Based, On-Demand Ride Services: Comparing Taxi and Ridesourcing Trips and User Characteristics in San Francisco (Working paper). Retrieved from https://www.its.dot.gov/itspac/dec2014/ridesourcingwhitepaper_nov2014.pdf

2. San Francisco Transportation Code Section 1113 \& 1124. Retrieved from http://library.amlegal.com/nxt/gateway.dll/California/police/policecode? $\mathrm{f}=$ templates $\$ \mathrm{fn}=$ default.htm $\$ 3.0 \$$ vid=amlegal:sanfrancisco ca $\$$ sync $=1$

3. Balding M, Whinery, T, Leshner, E and Womeldorff, E (2019). Estimated TNC Share of VMT in Six US Metropolitan Regions, Fehr Peers Report SF19-1016, Aug 1, 2019 , Retrieved from https://mynorthwest.com/wp-content/uploads/2019/08/TNC-VMTFindings.pdf

4. Cramer, J \& Krueger, A.B. (2016) Disruptive Change in the Taxi Business: The Case of Uber." American Economic Review, 106 (5): 177-82.14.

5. $\quad$ PFM Group Consulting \& Schaller Consulting. (2018). Evaluation and Recommendations to Improve the Health of the Taxi Industry in San Francisco(Rep.). Retrieved https://www.docdroid.net/iH0nhnd/final-pfm-schaller-taxi-industry-report-5118.pdf

6. Bureau of Labor Statistics. (2018, March 30). San Francisco-Oakland-Hayward, CA - May 2017 OES Metropolitan and Nonmetropolitan Area Occupational Employment and Wage Estimates. Retrieved from https://www.bls.gov/oes/current/oes_41860.htm\#53-0000

7. Bureau of Labor Statistics. (2018, March 30). San Francisco-Redwood City-South San Francisco, CA Metropolitan Division - May 2017 OES Metropolitan and Nonmetropolitan Area Occupational Employment and Wage Estimates. Retrieved from https://www.bls.gov/oes/current/oes_41884.htm

8. Bureau of Labor Statistics. (2018, March 30). 43-5032 Dispatchers, Except Police, Fire, and Ambulance. Retrieved from https://www.bls.gov/oes/current/oes435032.htm

9. ERI Economic Research Institute. (2018). Taxi Dispatcher Salary in San Francisco, California, United States. Retrieved from https://www.salaryexpert.com/salary/job/taxidispatcher/united-states/california/san-francisco

10. Hara Associates Inc., \& Corey, Canapary, \& Galanis. (2013, April 3). Best Practices Studies of Taxi Regulation: Managing Taxi Supply(Rep.). Retrieved https://www.sfmta.com/sites/default/files/Draft ManagingTaxi Supply 45 WEBversion04042043.pdf

11. Bösch, P. M., Becker, F., Becker, H., \& Axhausen, K. W. (2017). Cost-based analysis of autonomous mobility services. Transport Policy. doi:10.1016/j.tranpol.2017.09.005

12. Gordon-Bloomfield, N. (2012, February 15). San Francisco: Twice As Many Taxis Burn Half As Much Gas; Here's How. Retrieved from 
Nunes, A, \& Hernandez, K.D. (2020). Autonomous taxis and public health: High cost of high opportunity cost?

Transportation Research Part A: Policy and Practice. Vol 138, 28 - 36.

https://www.greencarreports.com/news/1072985 san-francisco-twice-as-many-taxisburn-half-as-much-gas-heres-how

13. Roberts, C. (2016, March 02). Uber Drivers' Long Hauls. Retrieved from http://www.sfweekly.com/news/uber-drivers-long-hauls/

14. Addison, J. (2012, February 09). San Francisco Doubles Taxi Fleet while Cutting Gasoline Use in Half. Retrieved from http:/www.cleanfleetreport.com/san-francisco-hybrid-taxis/

15. Bureau of Transportation Statistics. (2016). Average Cost of Owning and Operating an Automobile. Retrieved from https://www.bts.gov/content/average-cost-owning-andoperating-automobile

16. 2018 Ford Fusion Hybrid S FWD Specs. Retrieved from https://www.thecarconnection.com/specifications/ford fusion-hybrid 2018 s-fwd

17. California Energy Commission. California Average Weekly Retail Gasoline Prices $\begin{array}{lllll}\text { February } & 1996 & \text { Through } & \text { Current. } & \text { Retrieved }\end{array}$ http://www.energy.ca.gov/almanac/transportation_data/gasoline/retail_gasoline_prices $2 . h$ tml\#2017

18. State of California Department of Industrial Relations. Minimum Wage. Retrieved from https://www.dir.ca.gov/dlse/faq minimumwage.htm

19. Center for Neighborhood Technology. H T Fact Sheet: San Francisco, CA. Retrieved from https://htaindex.cnt.org/fact-sheets/

20. Kelley Blue Book. (2018, January 3). Average New-Car Prices Set Record High, Up Nearly 2 Percent In December 2017, According To Kelley Blue Book [Press release]. Retrieved from https://mediaroom.kbb.com/2018-01-03-Average-New-Car-Prices-SetRecord-High-Up-Nearly-2-Percent-In-December-2017-According-To-Kelley-Blue-Book

21. Palermo, N. (2013, August). What's the Right Down Payment on a Car Loan or Lease? Retrieved from https:/www.autotrader.com/car-shopping/whats-right-down-payment-carloan-or-lease-212702

22. ValuePenguin. (2018). Average Auto Loan Interest Rates: 2018 Facts \& Figures. Retrieved from https://www.valuepenguin.com/auto-loans/average-auto-loan-interest-rates

23. Auto Insurance Specialists. (2013, August 07). How Much Does it Cost to Own a Car in California? Retrieved from http://blog.aisinsurance.com/2013/08/07/how-much-does-itcost-to-own-a-car-in-california/

24. ValuePenguin. (2018). Average Cost of Insurance: Car, Home, Renters, Health, and Pet (2018). Retrieved from https://www.valuepenguin.com/average-cost-of-insurance

25. AAA. (2017, August 23). Your Driving Costs. Retrieved from https://newsroom.aaa.com/auto/your-driving-costs/ 
Nunes, A, \& Hernandez, K.D. (2020). Autonomous taxis and public health: High cost of high opportunity cost? Transportation Research Part A: Policy and Practice. Vol 138, 28-36.

26. Car Cleaning Guru. How Long Should I Spend Washing My Car? Retrieved from http://www.carcleaningguru.com/how-long-should-i-spend-washing-my-car/

27. Grilli, S. (2017, July 18). DIY or Buy: Car Wash Edition. Retrieved from https://www.groupon.com/articles/car-wash-cost-vs-at-home-wash

28. JBS Industries. (2016, December 19). Everything You Need to Know About Starting A Car Wash. Retrieved from https://www.jbsindustries.com/blog/starting-car-wash/

29. Search results: Car wash soap. Retrieved from https://www.amazon.com/s/ref=nb_sb_noss_1?url=search-alias\%3Dautomotive\&fieldkeywords $=$ car + wash + soap

30. Search results: Car washing kit. Retrieved from https://www.amazon.com/s/?ie=UTF8\&keywords=car+washing+kit\&tag=googhydr20\&index $=$ aps \&hvadid $=175225842956 \&$ hvpos $=1 \mathrm{t} 1 \&$ hvnetw $=\mathrm{g} \&$ hvrand $=176523264371$

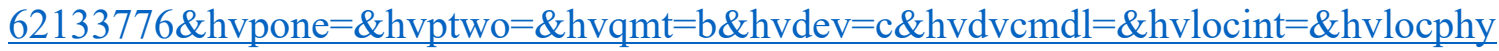
$=1014221 \&$ hvtargid $=$ kwd-17083823\&ref=pd_sl_1vlmoyserh $\_b$

31. United States Census Bureau. (2017, September 12). Income, Poverty and Health Insurance Coverage in the United States: 2016 [Press release]. Retrieved from https://www.census.gov/newsroom/press-releases/2017/income-povery.html

32. Monthly average fuel economy of new vehicles in US drops - report. (2018, January 05). Retrieved from https:/www.reuters.com/article/usa-autos-fuel-economy/monthlyaverage-fuel-economy-of-new-vehicles-in-us-drops-report-idUSL4N1P045H

33. San Francisco Municipal Transportation Agency. Residential Parking Permits (RPP). Retrieved from https://www.sfmta.com/permits/residential-parking-permits-rpp

34. Nelson/Nygaard and Dyett \& Bhatia (2015), Parking Structure Technical Report: Challenges, Opportunities, and Best Practices, Parking Reform Campaign, MTC (www.mtc.ca.gov); at $\quad$ www.mtc.ca.gov/planning/smart growth/parking/612/MTC Parking_Structure.pdf.

35. Ayala, R. (2014, July 9). Revised departmental guidance on valuation of travel time in economic analysis [Memorandum]. Washington, DC: U.S. Department of Transportation. Retrieved from https://www.transportation.gov/sites/dot.gov/files/docs/USDOT\%20VOT\%20Guidance $\%$ 202014.pdf

36. San Francisco, CA." Data USA. Retrieved from https://datausa.io/profile/geo/sanfrancisco-ca/\#demographics.

37. Transportation Fact Sheet. Retrieved from http://ridetowork.org/transportation-fact-sheet

38. Vaughan, S. (2016, November 16). Average Lifespan for U.S. Vehicles. Retrieved from https://berla.co/average-us-vehicle-lifespan/ 